University of Nebraska - Lincoln

DigitalCommons@University of Nebraska - Lincoln

3-10-2006

\title{
Sight-Reading Versus Repertoire Performance on the Piano: A Case Study Using High-Speed Motion Analysis
}

\author{
Brenda Wristen \\ University of Nebraska--Lincoln, bwristen2@unl.edu \\ Sharon Evfans \\ University of Nebraska - Lincoln, sevans1@unl.edu \\ Nikolaos Stergiou \\ HPER Biomechanics Laboratory, University of Nebraska at Omaha, nstergiou@mail.unomaha.edu
}

Follow this and additional works at: https://digitalcommons.unl.edu/musicfacpub

Digipart of the Music Commons

Commons

Network Kren, Brenda; Evfans, Sharon; and Stergiou, Nikolaos, "Sight-Reading Versus Repertoire Performance bRGRe Piano: A Case Study Using High-Speed Motion Analysis" (2006). Faculty Publications: School of Music. 8.

https://digitalcommons.unl.edu/musicfacpub/8

This Article is brought to you for free and open access by the Music, School of at DigitalCommons@University of Nebraska - Lincoln. It has been accepted for inclusion in Faculty Publications: School of Music by an authorized administrator of DigitalCommons@University of Nebraska - Lincoln. 


\title{
Sight-Reading Versus Repertoire Performance on the Piano:
}

\section{A Case Study Using High-Speed Motion Analysis}

\author{
Brenda Wristen, Ph.D., Sharon Evans, Ph.D., and Nicholas Stergiou, Ph.D.
}

\begin{abstract}
This study was intended to examine whether differences exist in the motions employed by pianists when they are sightreading versus performing repertoire and to determine whether these differences can be quantified using high-speed motion capture technology. A secondary question of interest was whether or not an improvement in the efficiency of motion could be observed between two sight-reading trials of the same musical excerpt. This case study employed one subject and a six-camera digital infrared camera system to capture the motion of the pianist playing two trials of a repertoire piece and two trials of a sight-reading excerpt. Angular displacements and velocities were calculated for bilateral shoulder, elbow, wrist, and index finger joints. The findings demonstrate the usefulness of high-speed motion capture technology for analyzing motions of pianists during performance, showing that the subject's motions were less efficient in sight-reading tasks than is repertoire tasks. Med Probl Perform Art 2006;21:10-16.
\end{abstract}

$\mathrm{P}$ ianists are frequently confronted with situations that necessitate adequate sight-reading skills. This widespread need for sight-reading at the piano may be due in part to pianists' participation in collaborative music-making, as professional pianists often sight-read in the course of collaborating with other musicians or accompanying choral ensembles. The size of the piano literature also contributes to the need, as the repertoire is so voluminous that no one player can be familiar with all solo and collaborative pieces written for piano. Recordings of piano literature tend to be restricted to the most well-known and familiar pieces, and recordings of pedagogical piano literature, in particular, are sparse.

The nature of sight-reading varies widely. The pianist might have a few minutes to examine a score or might have to

Dr. Wristen is Assistant Professor in the School of Music, University of Nebraska-Lincoln, Lincoln, Nebraska; Dr. Evans is Associate Professor in the University of Nebraska-Lincoln and Madonna Rehabilitation Hospital, Lincoln, Nebraska; and Dr. Stergiou is Director of the HPER Biomechanics Laboratory, University of Nebraska at Omaha, Omaha, Nebraska.

Presented in part as a poster presentation at the National Conference on Keyboard Pedagogy, Oak Brook, Illinois, August 3-5, 2005.

Primary funding for this study was through a grant-in-aid from the University of Nebraska Research Council. Data analysis was supported by a Faculty Development Fellowship awarded by the University of Nebraska at Omaha to Dr. Stergiou.

Address correspondence and reprint requests to: Brenda Wristen, Ph.D., 343 Westbrook Music Bldg, Lincoln, NE 68588-0100. Tel 402-472-1438; fax 402-472-1384; email bwristen2@unl.edu. read the music with little or no preparation. In any case, the sight-reading task may be viewed in direct contrast to a repertoire task, in which the pianist has engaged in weeks and often months of cognitive and physical training, thus gaining a high level of familiarity with the music being performed.

\section{DEMANDS OF SIGHT-READING}

Sight-reading entails a number of demands that can be distinguished from those inherent in the performance of practiced repertoire. Basic elements that must be attended to during sight-reading include:

1. Rhythm: meter, duration, patterns, accentuation

2. Melody: pitch, direction, movement (skips vs leaps, etc.), and patterns

3. Harmony: chord structure, chord progressions

4. Context: articulation, expressive markings, musical structure and form

In addition to these basic constructs, there are also more subtle cues-such as maintaining balance between the hands or attention to performance practice-embedded in the music that may or may not be rendered in a sight-reading attempt based on the experience and musical sophistication of the instrumentalist.

Prerequisites for successful sight-reading include the ability to recognize musical patterns, generate a large-scale performance plan to govern performance of the piece as a whole, and anticipate how the music continues. ${ }^{1}$ In addition to perceiving and decoding aspects of the score, successful readers must anticipate problems while continuing to observe musical markings and evaluate sight-reading execution in order to correct the performance as necessary. ${ }^{2}$

Piano sight-reading poses a special visual challenge. Looking at the musical score must be balanced with the need to look at the hand and fingers to accurately place them on various parts of the keyboard in order to play correct pitches. The pianist easily can lose his or her place in the score as the eye moves and refocuses. In contrast, rehearsed performance typically negates the visual difficulties of score reading, as memorization is common practice. Performance of practiced repertoire allows for free recall of musical materials and physical mastery of requisite motor skill patterns. Each time a repertoire piece is practiced, the pianist makes more inferences about correct pitches and other musical details. ${ }^{1}$ 
Underlying all of these cognitive and physical considerations is the daunting constraint of sight-reading with continuity, in "real-time," without stopping to decipher the written score or correct mistakes. Maintaining a continuous rhythmic pulse is paramount. The musician must keep playing during sight-reading, even if he or she executes notation improperly.

Studies conducted regarding sight-reading ability to date have fallen into three broad categories:

1. Cognitive/perceptual, including eye movements, perception of notation and other aspects of the score, and the influence of visual and auditory feedback

2. Factors affecting success in sight-reading achievement, including differences pertaining to specialization among pianists

3. Educational/pedagogical approaches, which focus on sight-reading acquisition or improvement with help of specific instruction or pacing devices.

The literature reviewed for the present study focused on the first two categories of sight-reading study.

Cognitive studies on sight-reading to date have primarily focused on determining what internal processes successful sight-readers use in comparison with those musicians who are less skilled or less experienced at sight-reading. Studies in this area to date have focused primarily on eye movements, ${ }^{3-}$ 5 pattern recognition and "chunking" musical details into larger perceptual units, ${ }^{6,7}$ and perception of musical notion within a larger context. ${ }^{8-10}$ Cognitive/perceptual studies have addressed the processing work done by the brain during the sight-reading task, rather than examining physical motions.

While motor execution has not been the primary focus in the aforementioned types of studies, several studies focusing on cognition during the sight-reading task have considered motor patterning outcomes in relation to cognitive processing. There is some merit to the traditional and intuitive pedagogical notion that the best way to improve sight-reading ability is to engage in sight-reading activity. Both performance accuracy and consistency of fingering correlate positively with expertise. ${ }^{11}$ Expert piano sight-readers develop rule-governed patterns of motor response in their fingers that are utilized on recognition of familiar visual notational patterns. As expertise increases, musicians are able to combine movements into variable patterns that appropriately execute musical notation.

Skilled motor performance in any human endeavor rarely consists of rigidly programmed motor sequences, where each individual movement arises invariably and inflexibly from the prior movement. Shaffer ${ }^{12}$ noted that expert pianists were able to develop a mental plan that specifically addressed the intended sight-reading outcome and employ a flexible motor programming system that efficiently enacted the required muscular contractions. It is thus apparent that skilled sightreaders have better developed and more flexible motor programming patterns when sight-reading at their instrument than do novice sight-readers.
Even for those players with this advanced motor pro gramming ability, it is likely that sight-reading is more physically awkward than the performance of repertoire that has been previously practiced. In their examination of pianists learning new repertoire, Halsband, Binkofski, and Camp ${ }^{9}$ found that as players moved from the beginning stages of working with a piece to more advanced interpretive and expressive phases, the perception of the task changed. Motor skills were less efficient during the early learning phases of a piece. As pianists began to perceive progressively larger metrical groupings as a result of practice, their motor patterns became increasingly more efficient. Just how these motor sequences become ingrained in pianists or other instrumentalists remains a question for further research.

As can be seen from a review of the literature, physical motion during sight-reading has not been a focus of research. Many pianists and piano pedagogues have asserted that they find the experience of sight-reading to be more physically taxing than performing or practicing repertoire pieces, and some further suspect that excessive sight-reading can expose pianists to injury. William Westney ${ }^{13}$ encapsulated this belief, saying: "There is certainly a direct link, though it has been little discussed, between high-level sight-reading and performance injuries."

This widespread perception underscores the unique challenges inherent in sight-reading, which until now have not been investigated from a quantitative scientific perspective. The purpose of the present study was to identify whether the use of motion-capture technology can identify quantifiable differences in the motions made by pianists when sight-reading versus performing practiced repertoire. If these differences do exist, the goal is to describe these differences and draw conclusions regarding motion efficiency based on the quantified data. Inefficient movement may contribute to muscle and tissue fatigue and pain and is often viewed as a factor in the development of various injuries. A secondary question examined whether differences in motion can be observed from one sight-reading attempt to the next, which may demonstrate adaptations of motor skills resulting from a single reading of a musical excerpt.

\section{METHODS}

The single participant signed an informed consent according to university Institutional Review Board guidelines and then completed a questionnaire that inquired about recent pieces performed and lifetime practice habits. Realizing that levels of pianistic experience do not correlate with age, nor does the level of sight-reading match the ability to sight-read proficiently, we made several crucial accommodations to allow for these variables.

The terms that pedagogues typically apply to experience level of pianists-beginning, intermediate, and advanced-do not have absolute meaning, and thus, for the purposes of this study, it was necessary to place some parameters around these terms. Repertoire level was designated as elementary, intermediate, or advanced by making arbitrary distinctions within 


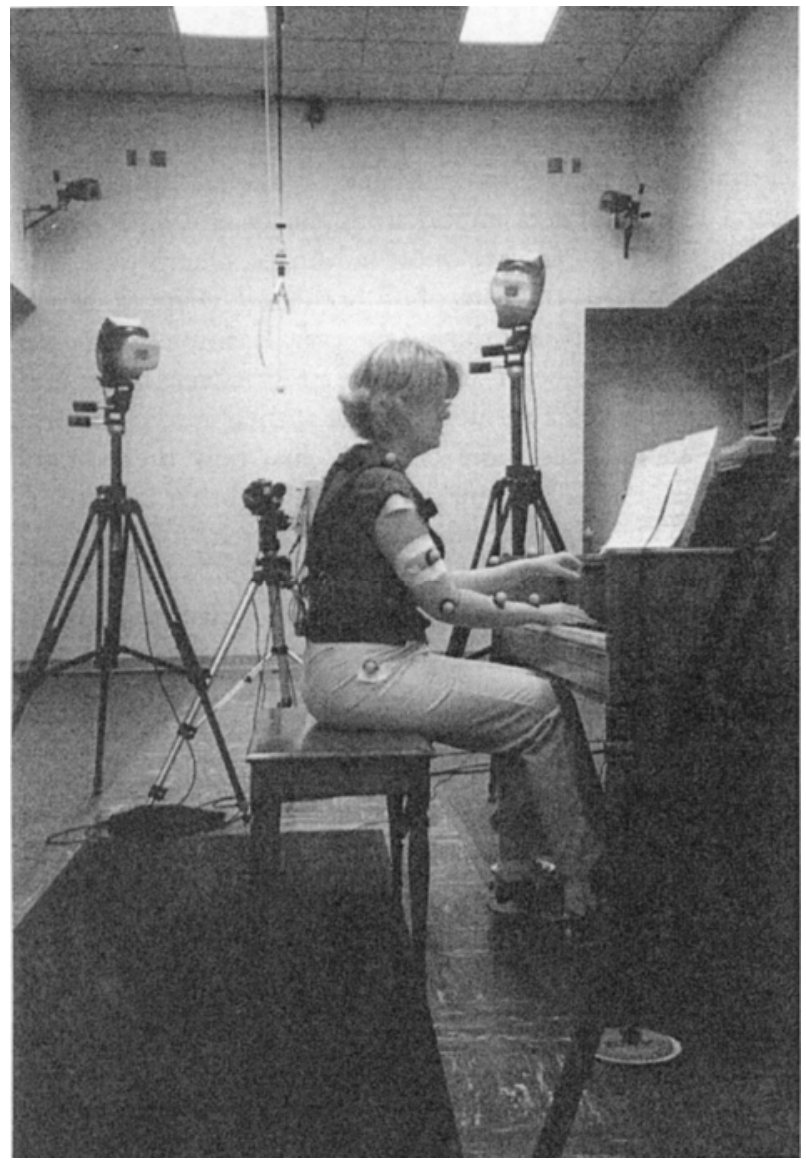

FIGURE 1. Instrumentation for data collection.

the leveling system employed by the Royal Academies of Music system. A "beginning" student was defined as playing in the first two levels of any method book, or below level 3 according to the Royal Academy of Music; intermediate levels were defined as encompassing levels 4 to 8 ; and advanced level was defined as anything at level 9 or above.

The subject chosen for the case study was a 23-year-old woman. She was designated as being of "advanced" experience level, since her repertoire, Chopin's B-Flat Minor Scherzo, fell above level 10 within the Royal Academy categorization system. She reported taking piano lessons for 19 years and was still taking lessons at the time of data collection. Her estimated lifetime practice total was $8,944 \mathrm{hrs}$.

There is a wide disparity of sight-reading abilities, even among expert pianists. Because sight-reading ability and repertoire level rarely correspond, during the participant's initial visit, a pretest was given to determine the level of sight-reading ability according to specific criteria. To determine the subject's unique sight-reading level, two sets of sight-reading materials were prepared: one for the pretest and one for data collection. Each set contained 15 levels of sight-reading of increasing complexity and difficulty. To ensure that the sight-reading encountered during data collection was true sight-reading (i.e., had never been encountered), the sight-reading excerpts that the participant played during the pretest was different from but equivalent to the data collection sight-reading. Equivalency of the two sets of sight-reading was verified by two additional piano pedagogy experts at peer institutions.

During the sight-reading pretest, a 10-point Likert scale was used to determine the subject's unique sight-reading level. Elements measured by this scale included the subject's ability to: maintain a steady, consistent pulse, play accurate pitches, observe tempo; employ reasonable fingerings, observe articulation and phrasing, observe dynamics and other musical markings, capture musical mood, and use appropriate pedaling.

The subject played multiple examples of varying difficulties until her score on the criteria listed fell within the range of 6 to 9 on a 10-point scale. Using these midrange measures helped the sight-reading task mimic real life - the sight-reading was playable yet maintained the element of challenge. Because the participant had to play numerous excerpts to make a determination of sight-reading level, the pretest was done on a separate day from data collection, to ensure that fatigue from these numerous readings would not impair data collection.

Data were collected in the Movement Sciences Center in the Institute for Rehabilitation Sciences and Engineering at Madonna Rehabilitation Hospital in Lincoln, Nebraska. In order to capture the motion of body segments, 20 reflective markers were placed on selected anatomic landmarks of the torso, right and left arms, and index fingers (Figure 1). Because placing markers on each finger would have been cumbersome and difficult for the infrared cameras to discriminate, the index finger was chosen due to its continuously active role during piano playing. A six-camera digital infrared optoelectronic system (Motion Analysis, Inc., Santa Rosa, CA) sampling at $120 \mathrm{~Hz}$ was used to capture the pianist's motions during performance.

Few studies have employed high-speed motion analysis to analyze the motions of musicians. Shan et al. ${ }^{14}$ used motioncapture technology in conjunction with surface electromyography and biomechanical modeling to study motions made by violinists while playing. Their findings demonstrated how information from multiple modes of assessment, including surface electromyography, high-speed motion-capture technology, internal load analysis, and biomechanical modeling, could be integrated to provide a fuller understanding of violinists' motions. The present study is the first to apply motion-capture technology to the study of pianists.

The subject performed two separate trials of two tasks of approximately 2 minutes apiece; these tasks consisted of a sight-reading excerpt and a "performance-ready" repertoire piece. The subject performed the same repertoire and sightreading excerpts for both trials of each task. The order of the two tasks was randomly determined by coin toss. Upon being presented with the sight-reading excerpt during data collection, the subject was instructed to begin playing immediately, with no preparation time. The participant selected her own repertoire, with the only stipulation being that it should be "performance ready." While memorization was optional, it 


\section{SCHERZO}

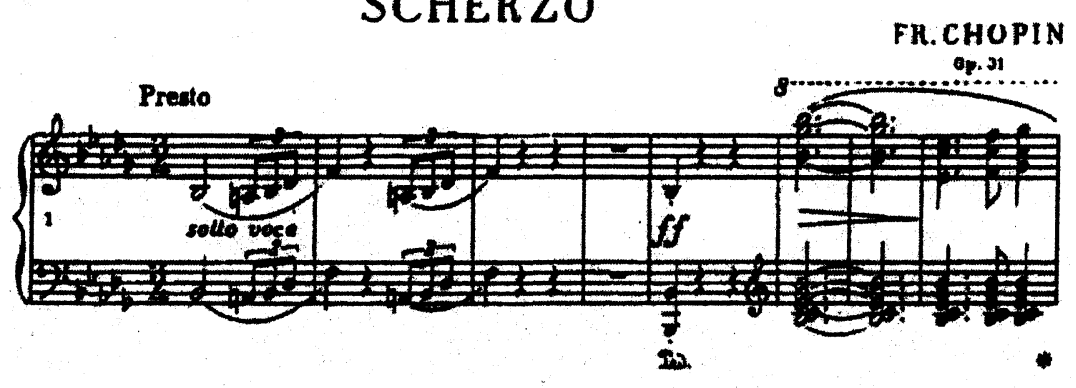

mm. 57-68

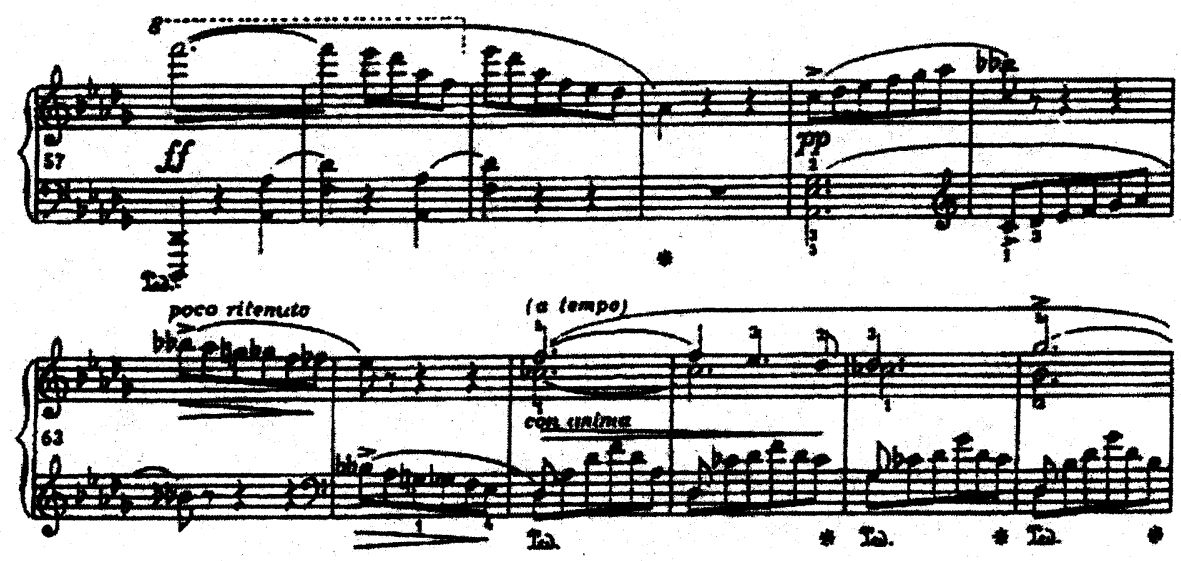

FIGURE 2. Excerpts from the subject's repertoire piece, Scherzo in B-flat Minor by Frederik Chopin (Frederik Chopin Institute, 11th ed., 1950).

was encouraged, as this is accepted performance practice among pianists. The subject played her repertoire selection by memory.

\section{RESULTS}

The repertoire piece played by the subject for both repertoire tasks was the Chopin Scherzo in B-flat Minor Opus 31 (Figure 2). She played from the beginning of the piece for a duration of 2 minutes. The sight-reading excerpt played was the second movement from Judith Lang Zaimont's Suite Impressions; entitled "Jazz Waltz" (Figure 3), and had not been encountered previously by the subject.

Angular velocity and angular displacement data were examined for the following joints: shoulder, elbow, wrist, and index finger. Angular velocity refers to how fast the marked body segments flexed-extended within a task, while angular displacement indicates how far those segments moved (range of motion).

For both angular velocity and displacement, the minimum and maximum values for each trial of both repertoire and sight-reading were identified for each data set. Subsequently, these two minimum values were subtracted from maximum values for each data set, providing a range of values for these two variables. This subtraction prevented a limited evaluation of the data by examining just the maximum or the minimum value, which has been identified in the biomechanical literature as inadequate. ${ }^{15,16}$

Angular displacement values provided the maximum actual range of motion. Increased values indicated a large amount of movement in terms of flexion-extension at the joint. Similarly, angular velocity provided the maximum range of values present in the data set. Increased values indicated faster movements in terms of flexion-extension at a joint. The mean value of the angular velocity maximum range and of the angular displacement maximum range of motion was then determined for each repertoire and sightreading trial (labeled $\mathrm{R} 1, \mathrm{R} 2, \mathrm{~S} 1$, and $\mathrm{S} 2$, respectively).

Angular displacements used by the subject are displayed in Table 1. The means of all the joint angles were combined to express a composite mean that is descriptive of the trial results in general. The subject used a greater range of motion in both her repertoire and sight-reading examples from the first trial to the second trial. The composite mean for angular displacement during the repertoire trials increased from 48.895 to 49.5325 on the left side and from 60.8975 to 66.805 on the right side. Similarly, the composite mean of angular displacement during sight-reading trials increased from 31.64 to 35.3525 on the left side and from 37.24 to 39.9475 on the right. The subject used less movement overall 

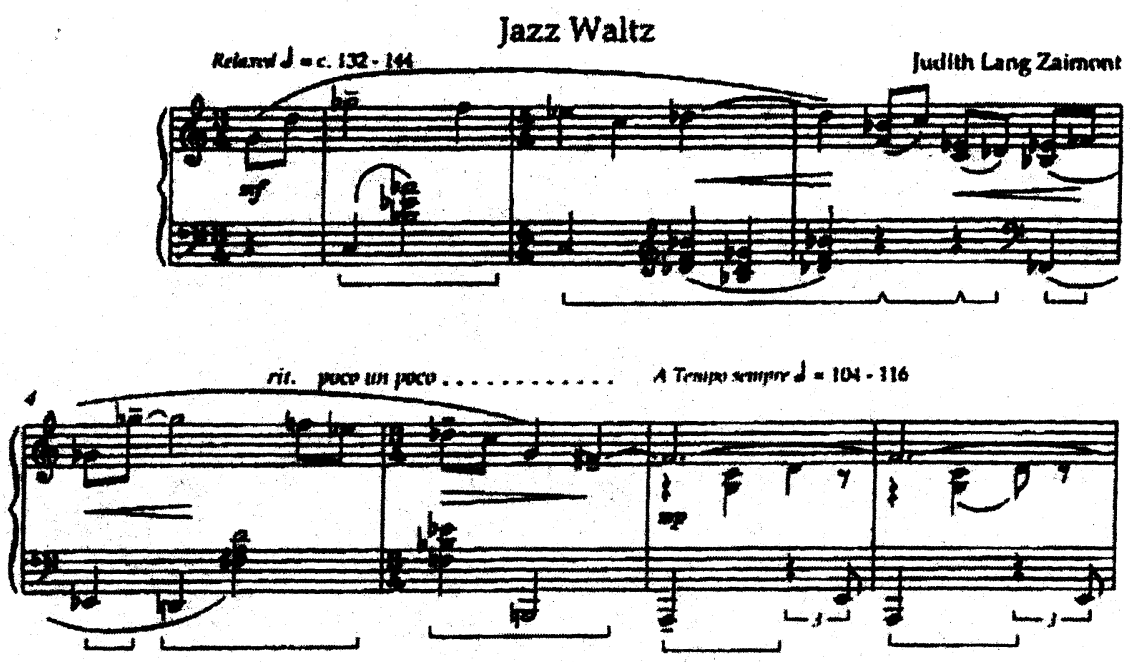

mm. 31-36
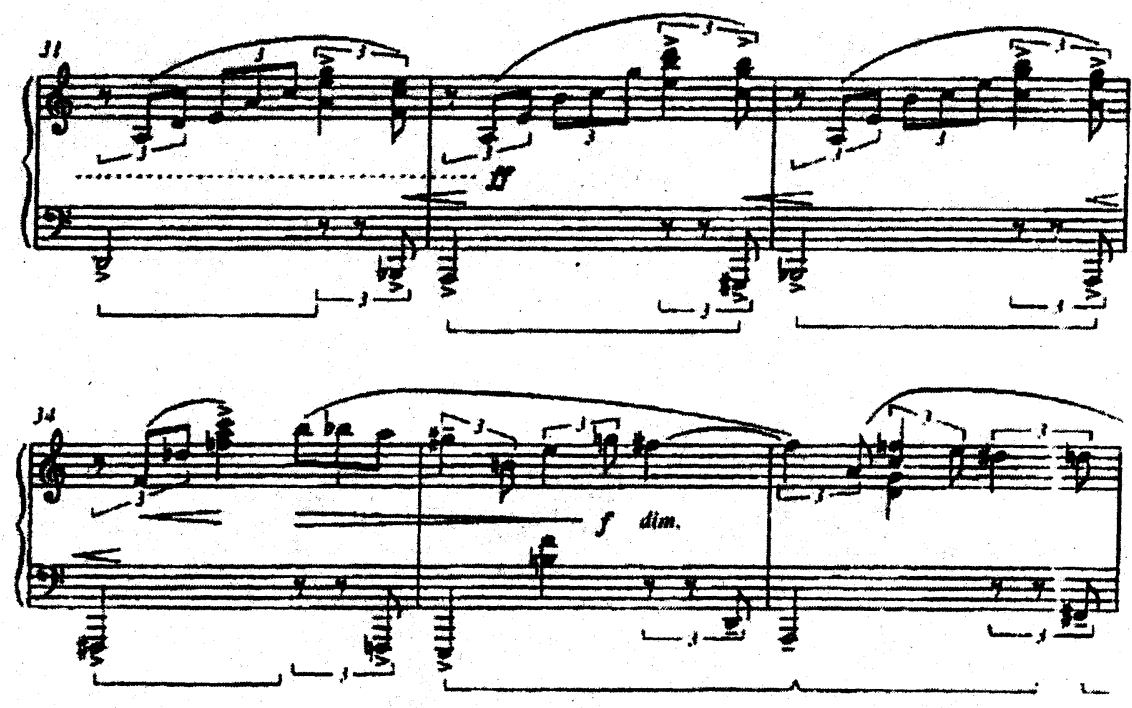

FIGURE 3. Excerpts from the subject's sight-reading, "Jazz Waltz" from Suite Impressions by Judith Lang Zaimont (@ Vivace Press, 2006; reprinted by permission www.vivacepress.com).

for the sight-reading in comparison with her repertoire piece.

In examining the composite angular displacement means for the right side, there is a difference between repertoire and sight-reading trials of $23.6575^{\circ}$ for the first trial (R1 compared to S1) and an even larger difference of $26.8575^{\circ}$ in the second trial (R2 compared to S2). This finding is interesting because the keyboard range of the sight-reading example is roughly equivalent to the repertoire piece, requiring the same degree of motion to place the upper body over the piano keys. However, the repertoire piece (Chopin Scherzo in B-flat minor), employs more frequent changes in position with both arms. For example, in the introduction, both arms are positioned to the left (bass) side of the keyboard and are then rapidly displaced to the upper registers of the piano (Figure 2). A third observation is that the pianists' movements on the right side of her body were higher. This finding may demonstrate right hand dominance.

The most significant finding with regard to the angular displacement data is that in both trials of sight-reading, the finger had almost double the motion of the other three joints. For example, in the first sight-reading trial (S1) on the right side, the subject moved her index finger $64.75^{\circ}$, while the shoulder, wrist, and elbow only moved $23.59^{\circ}, 22.72^{\circ}$, and $37.9^{\circ}$, respectively. This was not the case in the repertoire trials, where the movement of the elbow equaled or exceeded the movement of the finger. In the first trial of repertoire, the elbow moved $76.74^{\circ}$, while the index finger moved $65.54^{\circ}$. Because forearm movement as it lines up with individual fingers can be deduced from the motion of the elbow in space, this finding demonstrated that while sight-reading, the subject 
used more independent finger motion. While playing the repertoire excerpt, the subject used more coordinated motion patterns involving the forearm.

Several significant observations also were made in this case study regarding angular velocity, or the speed at which the identified joints were flexing and extending (Table 2). In the sight-reading task, smaller velocities were observed at all joints in comparison with the repertoire trials, which relates directly to the slower tempo of the sight-reading excerpt compared to the repertoire excerpt. In both the sight-reading and the repertoire tasks, velocity increased with movement from the top of the arm to the tip of the finger. This finding reinforces what piano pedagogues have long asserted-that the arm in piano playing demonstrates a "whip-like" motion.

The most interesting finding in relation to angular velocity is that while velocity from the first repertoire task to the second repertoire task did not change markedly, there was a definite increase in velocity from the first sight-reading task to the second sight-reading task. This finding was not a function of tempo, which remained roughly the same from S1 to S2, but indicated the subject's adaptation to task demands. The increase in velocity in the left hand is notable because this particular sight-reading excerpt required the left hand to locate bass notes that are isolated by register. The subject improved her velocity in her left hand by $72.5475^{\circ}$ per second from the first to second sight-reading trials (S1 to S2). Thus, the greater velocity used in the second trial indicated that the subject gained some level of neuromuscular familiarity with the sight-reading excerpt from a single reading. This last observation is also bolstered by the angular displacement findings. In comparing S1 to S2, there was an increase in flexion/extension angles at all the joints, which would tend to show a greater coordination between all the segments of the playing apparatus rather than over-reliance upon finger motion as previously discussed. Both of these observations support the conclusion that this subject improved her motion efficiency with only a single reading of the sight-reading excerpt.

\section{CONCLUSIONS}

Initial findings from this case study demonstrate the efficacy of using high-speed motion-capture technology to study the movements made by pianists in real time. Piano playing has been associated with a high incidence of injury. ${ }^{17,18}$ Although the exact etiology and pathology of injury development remain largely unknown, it is likely that a number of factors contribute. Factors that have been identified include lifestyle/behavioral factors, a sudden increase in the time and/or intensity of practice, change in playing technique, and intrinsic factors such as size, strength, muscle tone, flexibility, and genetic predisposition toward injury. ${ }^{19,20}$. While technique may be less influential than genetics, it is at least a controllable factor.

Exploration of piano technique using objective measurement tools, such as high-speed motion-capture technology, allows for detailed examination of pianists' motions, offering
TABLE 1. Angular Displacement (in Degrees) for the Subject in All Four Trials

\begin{tabular}{cccccc}
\hline & Shoulder & Elbow & Wrist & Finger & Mean \\
\hline LEFT & & & & & \\
R1 & 38.18 & 59.19 & 42.14 & 56.07 & 48.8950 \\
R2 & 36.95 & 53.92 & 39.92 & 67.34 & 49.5325 \\
S1 & 18.28 & 25.82 & 30.25 & 52.21 & 31.6400 \\
S2 & 23.08 & 32.27 & 34.19 & 51.87 & 35.3525 \\
RIGHT & & & & & \\
R1 & 42.24 & 76.74 & 59.07 & 65.54 & 60.8975 \\
R2 & 51.48 & 80.79 & 55.22 & 79.73 & 66.8050 \\
S1 & 23.59 & 22.72 & 37.90 & 64.75 & 37.2400 \\
S2 & 25.40 & 30.51 & 39.66 & 64.22 & 39.9475 \\
\hline
\end{tabular}

$R 1$ and $R 2$ represent trials of repertoire piece, while $S 1$ and $S 2$ denote sightreading trials.

TABLE 2. Angular Velocity (in Degrees per Second) for the Subject in All Four Trials

\begin{tabular}{cccccc}
\hline & Shoulder & Elbow & Wrist & Finger & Mean \\
\hline LEFT & & & & & \\
R1 & 241.85 & 477.03 & 691.66 & 812.24 & 555.6950 \\
R2 & 224.32 & 555.96 & 511.61 & 741.72 & 508.4025 \\
S1 & 106.21 & 234.25 & 396.55 & 530.10 & 316.7775 \\
S2 & 125.07 & 265.38 & 442.81 & 724.04 & 389.3250 \\
& & & & & \\
RIGHT & & & & & \\
R1 & 207.09 & 308.80 & 730.34 & 959.02 & 551.3125 \\
R2 & 238.89 & 305.31 & 639.81 & 952.60 & 534.1525 \\
S1 & 87.86 & 176.07 & 427.83 & 711.63 & 350.8475 \\
S2 & 90.41 & 236.53 & 488.26 & 640.52 & 363.9300 \\
\hline
\end{tabular}

$R 1$ and $R 2$ represent trials of repertoire piece, while $S 1$ and $S 2$ denote sightreading trials.

data beyond that visible to the naked eye of the piano teacher. Use of high-speed motion analysis can help piano teachers identify potentially problematic motions in pianists' technique and enable them to make more exact pedagogical recommendations to students that will help them maximize their motor efficiency at the piano and avoid potentially deleterious movements.

\section{REFERENCES}

1. Lehmann AC, Ericsson KA: Performance without preparation: structure and acquisition of expert accompanying and sight-reading performance. Psychomusicology 1996; 15:1-29.

2. McPherson GE: Factors and abilities influencing sightreading skill in music. J Res Music Educ 1994; 42:217-231.

3. Sloboda JA: The eye-hand span: an approach to the study of sight-reading. Psychol Music 1974; 2:4-10.

4. Sloboda JA: Phrase units as determinants of visual processing in music reading. Br J Psychol 1977; 68:117-124.

5. Furneaux $\mathrm{S}$, Land MF : The effects of skill on the eye-hand span during musical sight-reading. Proc Royal Soc Lond Series B 1999 ; 266: 2435-2440.

6. Goolsby TW: Profiles of processing: eye movements during sightreading. Music Percept 1994; 12:97-123. 
7. Waters A, Underwood G: Eye movements in a simple music reading task: a study of experts and novice musicians. Psychol Music 1998; 26:46-60.

8. Waters A, Townsend E, Underwood G: Expertise in musical sight reading: a study of pianists. $\mathrm{Br}$ J Psychol 1998; 89:123-149.

9. Halsband U, Binkofski F, Camp M: The role of the perception of rhythmic grouping in musical performance: evidence from motor-skill development in piano playing. Music Percept 1994; 11:265-288.

10. Sloboda JA: The Musical Mind: The Cognitive Psychology of Music (rev. ed.). New Yorke Oxford; 1993.

11. Sloboda JA, Parncutt R, Clarke EF, Raekallio M: Determinants of finger choice in piano sight-reading. J Exp Psychol 1998; 24:185-203.

12. Shaffer LH: Performances of Chopin, Bach, and Bartok: studies in motor programming. Cogn Psychol 1981; 13:326-376.

13. Westney W: The Perfect Wrong Note. Pompton Plains, NJ: Amadeus Press; 2003.

14. Shan G, Visentin P, Schultz A: Multidimensional signal analysis as a means of better understanding factors associated with repetitive use in violin performance. Med Probl Perform Art 2004; 19:129-139.

15. Stergiou N, Buzzi UH, Kurz MJ, Heidel J: Nonlinear tools in human movement. In Stergiou N (ed): Innovative Analyses of Human Movement. Champaign, IL: Human Kinetics; 2003: pp 63-90.

16. Stergiou N, Bates BT, James SL: Asynchrony between subtalar and knee joint function during running. Med Sci Sports Exercise 1999; 31(11): 1645-1655.

17. Manchester RA: Medical aspects of musical development. Psychomusicology 1988; 7(2):147-152.

18. Sataloff RT, Brandfonbrener AG, Lederman RJ: Textbook of Performing Arts Medicine. New York: Raven Press; 1991.

19. Fry HJH: How to treat overuse injury: medicine for your practice. Music Educ J 1986; 72(May):44-49.

20. Brandfonbrener AG: The medical problems of musicians. Am Music Teacher 1988: April/May (37/55):11-13 ff. 